\title{
COLLABORATIVE METHODS IN RESEARCHING CITY BRANDING: STUDIES FROM HONG KONG, SHANGHAI, AND SYDNEY
}

\author{
JOHN GAMMACK* and STEPHANIE HEMELRYK DONALD† \\ *Griffith University, Meadowbrook, Australia \\ $\dagger$ University of Technology, Sydney, Australia
}

\begin{abstract}
This article illustrates and reflects upon the nature of inquiry appropriate to the question of place branding, in particular, world city branding. Disciplinary research traditions including cultural studies, film studies, marketing, and psychology offer conceptual categories and valuable modes of access to this area, and our concern here is to examine whether these compete or converge in forming understanding. Noting both the benefits and challenges of working across quite different paradigms of thought, vocabulary, and expected outcome, we discuss the possibilities of mutual shaping or influence in interdisciplinary inquiry. Acknowledging issues in establishing a working and meaningful discursive field across disciplinary boundaries, interests, and methodological habits, we illustrate, using a range of qualitative, projective, and quantitative methods, the collection, evaluation, and analysis of primary and secondary data in a current project. This looks at the major Pacific Rim cities of Sydney, Hong Kong, and Shanghai, and particular issues of their brand identity. While all three cities compete on the world stage for events, tourists, and investment, they also are at the center of distinct film traditions, and have been rendered variously in popular imagination. We examine the representation of the city in the mind of some of its publics, and the relation of this to the requirements of branding. We find common ground in critical categories including narrative, everyday life, and color, and view these as a plexus from which various discipline-focused inquiries may proceed. We also discuss how central notions of identity, character, and representation are conceptualized differently within disciplines, and note implications for place-branding theory. We conclude that greater cross-disciplinarity is required for appropriate understanding, and that both tourism marketing and cultural (especially film) studies can learn from each other.
\end{abstract}

Key words: City branding; Color; Narrative; Film studies; Interdisciplinary research

\section{Introduction}

The field of tourism has a rich set of source disciplines and associated modes of thought from which its problematic may be approached. Dynamism, plurality, and contention in contemporary social enquiry is evident (Denzin \& Lincoln, 2000), inter- and multidisciplinarity has been theo- 
rized for some time, and in contemporary academic fields such as tourism and cultural studies, consciousness of stance and assumptions is common.

The project reported here, Branding Cities on the West Pacific Rim, started in 2000, when the authors began forming an interdisciplinary research group to pose and answer cross-disciplinary questions, highlighting how disciplines differ, and why they must differ in order to answer the problems they address. The researchers were obliged to reexamine their practices and acknowledge parallel contributions unavailable through the normal restrictions of their disciplines. Discussion then with senior tourism officials indicated that global cities-already a serious topic for film theoristswould provide the depth we sought for an interdisciplinary enquiry, while highlighting some specific requirements and expectations of the various audiences for, and stakeholders in, these answers. We discovered how online destination marketing could transform everyday experience to address the affective sensibilities of prospective tourists (Gammack, Goulding, \& Seow, 2002), and questioned how this differed from other powerful media (e.g., film), which also use locations (Donald \& Gammack, 2001a, 2001b).

We consciously adopted a collaborative research strategy, requiring articulation of what that meant for our investigation. Collaborative research epistemology has been considered in other fields (Eloff et al., 2002), where ongoing transformations of understanding, multiple voices, and emergent research designs characterize an inquiry. Our own backgrounds are respectively "business school" and "cultural studies," and connotatively cast as focally "pragmatic" and "critical." Although perhaps a clichéd oversimplification of our roles, we chose to maintain this typecasting to heighten the creative tension in the study, and to seek a fertile middle ground.

Apart from strategic research issues, contingent issues of conceptualization and definition also required negotiation before data collection could commence. The understanding of "city," for example, might naively be equated with the physical place, quantified and differentially ranked on objective criteria. Or it might be understood instead as an infinitely mutable and imaged conception operating essentially in a global media space with only tangential reference to the natural resource. The various audiences for any descriptive findings on the city could respectively be alienated or disengaged by the different referents involved, and the relevance of the background literatures harder to establish and extend, without reverting into an essentially disciplinary understanding.

Similarly "branding" brings the baggage of a marketing conceptualization, traditionally referenced largely to research on personality and business communication. Anthropomorphic constructs such as essential attributes and characteristics, identity, image, and evolution, together with business notions of brand management, positioning, value, and equity, all shape understanding of how a brand can offer a distinctive proposition that resonates rationally and emotionally with its targets. For brand designers, branding the city encompasses an articulation of corporate identity where urban space performs place as if it were an extremely large and complex company interest. A strategic brand platform has five core aims: "an immediate recognition from the market, an attractive proposition for the market, a statement of sustainable difference from other products, long-term viability, and positive susceptibility to various aspects of development" (Temporal, 2000, p. 51).

The branding literature has developed from a product/market tradition, and despite the field's increasing sophistication, questions surround the concept's basic applicability if it requires a city to be identified and viewed as a consistent product, and whether the implied market focus is feasible or desirable. Issues entailed when identities are contested, plural, and evolving, and when operation is in multiple markets and across demographics, set problems for campaigns relying on the consistency of image and position. In cultural studies extensive research into categories of identity and identification exists-could this be relevant to "branding" cities? Could work in cultural studies extend the theoretical base of "branding science"; conversely, can it learn something from the solutions forced by the pragmatic and commercial requirements of branding? Do these fields of enquiry compete with, converge with, or exist independently of the other with nothing communicated in either direction? 
In this work we frame our methods, data collected, and interpretation against this background, attempting to establish a lingua franca to which a range of studies can relate, from various literatures, and perhaps with different focal agendas. Thus we are not asking "What is the brand for Sydney?" and then doing market research, nor yet "How is the political identity of Hong Kong understood through the semiotics of its officially branded communications?" We are, however, concerned to identify the sorts of constructs and methods that allow these types of questions to be asked conjointly, and their findings related sensibly through bridging theories cognizant of tourism, culture, and communication research. We begin therefore with a general consideration of relevant background literature.

\section{Branding and Cities}

Destination marketing and promotion is not new, and documentation can be traced back to the beginnings of tourism. Ward (1998) for example, describes the selling of places from frontier days and Victorian era resort visitation to the reinvention of postindustrial cities such as Glasgow. While many examples of successful destination marketing campaigns can be found for cities, regions and countries, if cities are to attract and retain visitors, industry, investment, or creative capital (Florida, 2002), or appeal to new or upscale residents, they have to position themselves in the public mind as having a relevant distinctiveness from competitors. This entails a deeper project of place branding, entailing strategic identification of the sustainable values, essence, image, and character and enduring beyond temporary slogans and campaign interpretations.

Although place branding is a relatively recent idea, Olins (2004, p. 152) notes that projecting national identity and reputation is a much older, analogous activity. Cities and regions with smaller budgets can benefit through relatedness to a national brand: a conscious approach to managing national brand architecture means that locales inherit the benefits of national image. Morgan, Pritchard, and Pride (2004) examine destination branding with attention to the "unique destination proposition," [cf. the unique selling proposition
(USP) concept of product differentiation in a marketplace]. Their book's case studies include Shanghai, Wales, Western Australia, and New Zealand, demonstrating examples of sophisticated branding exercises.

In time, a city or a country's public image can change. Branding can play an active role here, valuable when a location is "unknown," or has suffered some bad press. There is a trade-off between image and identity here, balancing what is substantially true with a projection of what is aspired to, or idealized as essential and valued qualities. A location may not always be sunny, but it may be thought of that way, and it may usually be true, or remembered as true.

Slogans can reinforce brand values and play a role in image projection. The "Glasgow's miles better" campaign successfully changed a previously negative perception of Glasgow among commercial decision makers (City of Glasgow, 2004). The "I (love) New York" slogan has been successful in promoting New York as well as in its original aim of attracting tourists. Both the slogan and an eponymous song have been unofficially adopted as state emblems. City image promotion now extends beyond tourism, involving permanent infrastructure for events and sponsorship deals (Stohr, 2003).

Clever advertising alone is deemphasized in such brand building, where conveying the proposition establishes and validates desired perceptions. Apart from the "authentic reality" of a place, brand serves an aspirational function-how (a city) would like to be (seen), surviving temporary volatility in its image, and where slogans can perform a valorizing role. Many slogans, however, convey nothing distinctive about a location and as such are unlikely in themselves to sell a place. Pike (2004) examined a range of positioning slogans used in marketing Rotorua since 1850 , questioning whether the short-term use of particular slogans indicates campaign ineffectiveness, or the lack of a long-term commitment to brand building. If slogans are short term, interchangeable, and substitutable, do not reflect the underlying reality, and send mixed or meaningless messages, branding based on them may be ineffective, and longer term strategies and associated campaigns are indicated. In Hong Kong especially, there are place 
histories that may come closer to retrieving the character of the city in the long term than either "East meets West" or "Asia's Global City."

Logos convey shorthand visual messages characterizing identity and perhaps brand values in a media environment characterized by information overload, hypercompetition, and short time frames. Color and stylized iconic or symbolic references are often critical design choices in conveying messages. Logos also usually last much longer than campaign slogans: accordingly it is more important that they encapsulate or connote an enduring identity. Necessarily designs effective across different media platforms, logo designers give considerable thought to their semiotic characteristics; often this follows elicitation of the values and qualities the encapsulation represents.

What does it mean to apply these notions to branding cities, with their multifaceted nature, their various stakeholders and publics, and their changing geopolitical roles? Are brand value commitments mediated and understood in film representations? And is this best investigated as a modernist project, seeking a distinctive encapsulation of unique essence and identity that differentiates cities from their competitors, or do logos and slogans here play a different role in brand building and evolution, conceived as a postmodern exercise of shifting spaces, interpretations, and role experiences, in keeping with a similar turn in other aspects of tourism theory (Uriely, 2005)?

Great cities have a depth of story and particular histories to inform their images. In film, location and its treatment by the camera and editors are essential to the development of narrative and to its emotional impact on the audience. How does place value in film act upon the place value of a tourism destination, and together support an idea of the city in the minds of residents and visitors? We will ask how historical shapers of identity feature in tourism or film representations by reference to the temporal constructs of nostalgia, everyday life, and aspiration, which provide structures of attention for understanding cities (Donald \& Gammack, 2004). These are recognized generic modes of film expression and potentially feature in propositions and imagined characterizations.

Three cities have been chosen to investigate these issues: Sydney, Shanghai, and Hong Kong.
Our selection was based firstly on the fact that each has a strong cinematic identity, as production centers, as locations memorialized in film, or both. Secondly, all three cities are gateways and major tourist destinations. Thirdly, they have a shared geopolitics complexifying their identity issues. All three share aspects of settlement and colonization, but a gulf of experience also separates and distinguishes them. The Chinese cities have traces-in Hong Kong's case still very deep and recent-of European visitation and activity (Carroll, 1999). Sydney's origin as a European city on indigenous land is the typical Australian story, but it has also a long engagement with China, through trade, production, labor, and immigration.

The article proceeds as follows. We report a cross-section of findings from a series of studies we have conducted in Sydney, Shanghai, and Hong Kong. For reasons of space and scope we only detail indicative results here; fuller details of the empirical work are available in other papers and in Donald and Gammack (in preparation). We outline a bricolage of methods we have used with a view to building an understanding of how city branding might be collaboratively investigated. We aim to illustrate the methods' qualities, with suggestive results, finishing with a reflexive consideration of our approach, and what we have learned about the branding of these world cities.

\section{Methods}

Our chosen data collection methods often involved a process of shared mental mapping (cf. Elkins, 2002). We use the term maps generally to refer to any representation of views and ideas: our maps are literal and conceptual, direct and derived, verbal and visual, individual and socially held, impressionistic and fact based. This range of methods and representations is intended to identify contours along which the city is rationally understood, and the affective qualities associated with those for its public.

Because branding is an emotional as well as a rational/functional relationship, we consider it important to find an access to these feelings and to probe on the emotional logic that informs much decision making (Damasio, 1994). Part of our wider mixed methods strategy, projective tech- 
niques are useful in going beyond socially acceptable verbal statements to surface the emotional and sensory associations and subconscious resonances that respondents bring to an issue (Livingston, 2004). Projective techniques invite unconstrained expression on behalf of respondents, who project themselves into the task, and are usually experienced as enjoyable activities. We now report some individual studies from our project.

\section{Interviews With Professionals}

The first set of maps were verbal, free-form interviews inviting people with varying types of local expertise to enunciate their idea of the city through a particular medium, cinematic or touristic. Establishing rapport first (Madriz, 2000, p. 845 ), our collaboratively designed questionnaire phrased questions to evoke a natural, conversational atmosphere. We interviewed various film professionals in each city, and asked parallel questions of city marketers and tourism chiefs. Openended, general questions encouraged personal responses and addressed both literal and figurative themes of place character and narrative. We asked about the character of the city, about the moods and colors, and their expression in participants' professional activity. Individual interviews usually lasted around 1 hour, and participants' professional interest in our work and its outcomes made for effective engagements. Some respondents in offices responsible for marketing their city generously provided official written materials and confidential background research documents that helped our understanding. These interviews also validated the "official stories" that could be detected from content analysis of tourism publicity materials.

Thus, for Sydney, city marketers consistently referred to the iconic Opera House and Harbour Bridge, and how the harbor itself gave life, beauty, and vibrancy to the experience. Marketers noted how the blue water and typically blue sky meant the city "always looked blue," and together with the yellow of the sand, motivated a color scheme often used in marketing communications. This was readily verified informally by direct experience, and by examination of logos from relevant bodies responsible for marketing and tourism busi- ness development for Sydney, including Tourism NSW and Sydney Harbour Foreshore Authority. Logos were downplayed in importance for Sydney, however: "Logos won't sell the city ... look out of the window - that will sell the city" (Tourism marketer, Sydney). The same marketer also said: "we have a palette of colors that we use ... you can look at some colors and say 'that's not Sydney' but you can write it in any font or typesize and (it will work)."

For Hong Kong, the branding situation, and indeed the whole issue of Hong Kong's identity, had been very dynamic, particularly since 1997 . An official unit, Brand Hong Kong, had been set up and among other activities focuses on associating the city with approved major events (Brand Hong Kong, personal interview, April, 2004). Brand Hong Kong provided research identifying five brand values (progressive, stable, high quality, free, and opportunity) and these have appeared in media, including promotional films on their website (brandhk.gov.hk) and in full color pages in the newspapers. [For example, the Hong Kong Economic and Trade Office advert in The Australian (Asian supplement) 3/23/2005 begins "Think of a city that is progressive, free, stable, where opportunity abounds and quality is premium."] Although Hong Kong's branding slogans in recent years have been criticized (Gentle, 2003), it is possible that their turnover is consistent with a rapidly changing city, whose brand is essentially itself, as various interviewees suggested, both within and outside Hong Kong.

\section{Focus Groups and Film}

We have also run focus groups, taking extensive notes from discussions among individuals in the same professional group. In most cases participants knew each other or had encouraged one another to attend. We also ran focus groups of residents in the cities themselves, particularly international students, who could provide a surrogate for a tourist or general visitor perspective. For professional groups, Sydneysiders working outside Sydney provided an analogous opportunity for a comparative perspective to emerge. Conversation was structured through a version of the individual questionnaire from the first set of studies but the 
direction of conversation often lingered on themes where the participants felt most passionate, conversant, and competent in their responses.

For example, one focus group held in Brisbane (June 2003) brought together production designers, cinematographers, and film theorists to discuss Sydney as a location. However, given that all participants were now based in Queensland (although none considered themselves "Queenslanders") the conversation quickly turned to a comparative discussion of Brisbane and Sydney as cinematic sites in the Australian film industry. Quotes such as "Sydney has views everywhere whilst Brisbane has just the view of the river" (Respondent 2) and "Sydney is a place where young people go to find themselves, like New York, London...." (Respondent 3) showed the perceived superior visuality of Sydney, and its status as a world city offering the potential for rite-of-passage, coming-of-age, or making-it stories where the requisite range of character and possibility is available for its aspirants.

In Hong Kong in late 2003, a focus group was held with eight audience members at the Hong Kong Film Archive, who had attended a retrospective screening of the films of Lao Dun, an early 20th Century Cantonese director and comic actor. Other than one Singaporean all participants were born and raised in Hong Kong and were of Chinese ethnicity, but described their nationalities variously as British (1), Hong Kong (3), and Chinese (3). Following a series of focused conversations about Cantonese film, the visual characteristics of Hong Kong city (cinematic and actual), the relationship of the city and its residents, and the tone and feeling of Hong Kong as a lived experience, respondents were asked to assess (on a 5point scale) the posited structures of attention: nostalgia, everyday life, and aspiration. The values they gave indicated how they experienced the city, but this was not treated quantitatively, other than to note that all ratings volunteered were 3 or above, suggesting that the structures of attention were meaningful, not mutually exclusive, and reflected different kinds of strong engagement with the city. It was not our experience that adopting this method presented any cultural barrier to communicating openly, despite differences in age and gender.
While detailed content analysis was inappropriate, based on evident trends and frequency of responses some observations can be made. Half the respondents were over 40 years old, and they talked about Hong Kong as a place with which they had deep affinity, using terms such as "love," "belonging," and "motherland" to describe it. Quickly understanding the questions on character of the city, they offered character descriptions (collated here) including: "cohesive and energetic, hilarious, cold, pragmatic, passive, selfish because it's a family not a nation, materialistic, vigorous, adaptable, and optimistic."

Nostalgia and everyday life were highly rated overall and, although present, comparatively less aspiration was evident in ratings and discursive descriptions of the city. Our research assumes that the experience of film is, in part, a phenomenological engagement with place and we triangulated such comments with independent film analysis and critique. Several films viewed in the HKFA were marked as nostalgic and inimitably Hong Kong. For example, Stanley Kwan's film Rouge (1987) is a text that addresses nostalgia in a romantic story of searching and where Hong Kong is summarized as a cluttered space where the present literally topples the sites of the past.

In 2003 we found that interviewees were anxious to articulate, on film and in theater, but also in conversation, a history of Hong Kong that would remember its Chineseness without forgetting its radicalism, its internationalism, and its suffering. This has been articulated in contemporary films sponsored by the Tourism Commission and the Hong Kong Film Directors Association (Donald, 2004). The histories indicated in Rouge shape Hong Kong and its character in a way that it is hard to imagine applying in Sydney, which our interviewees suggested was "not big on nostalgia."

By contrast, asking these same questions in Sydney produced a definite bias towards "aspiration" in the professional judgment of one noted visiting documentarist. Judged on the basis of a 20-year career but only a tourist/visitor experience of Sydney, his "idea of the city," developed through watching 50 Sydney films and particularly in the reading of Looking for Alibrandi, was that the film was outstandingly successful as an aspirational tale about Sydney. He argued that aspiration 
was best summed up in the Sydney context as an ongoing narrative of the city as a place of contrasts, where peace is only secured by putting one's aspirations aside (as in Alibrandi), or in retuning them to nonmainstream values, as in Muriel's Wedding.

Aspiration and individual status are represented by location within Sydney. Among the aspiring protagonists, only Muriel in Muriel's Wedding is privy to the view of the harbor (bridge, opera house, boats, and water) from their homes. The view is always a visual depiction of the very rich. The contemporary novel and telemovie Hell has Harbour Views (Beasley, 2001) also takes as a motif the increasingly enviable views from higher storied offices as the career ladder is climbed. Nic Roeg's 1971 film Walkabout a view of the harbor and bridge can be seen in the last scene of the film from the home of the central protagonist, where a materially comfortable domesticity is signaled, in strong contrast with the rest of the film. This solitary status symbol is an underlying theme throughout many Sydney films, and the harbor figures largely in TV series and films of everyday life.

\section{(Color) Survey}

In keeping with our use of mixed methods we transformed our questionnaire into various forms of survey instrument, seeking to validate the generality of particular suggestions and insights made by interviewees and in focus groups. In this section we report one aspect of this-restricted to one online survey, and addressing the specific issue of color. We used a projective technique for these questions, asking "If (Sydney) was a color, what would it be and why?" In other surveys we had asked this question verbally, and also by reference to a printed color chart of a representative palette. There are several methodological issues in asking such a question. Briefly, a lexical category of "blue" does not guarantee the same "blue" for everyone, and qualifying nuances verbally does not overcome this. Presenting a set of color chips or swatches does not exhaust the color space, and with over 7 million distinctly perceptible colors possible, logistics of data collection and statistical analysis are formidable. Finally, perception of colors is affected by viewing context: the influence of surrounding colors, ambient light levels, and computer display or printing limitations all affect perception and imply considerable experimental controls to study reliably. Given the nature of our investigation however, such fine detail was inappropriate, and eliciting broad, yet sufficiently distinctive, impressions was considered sufficient. We used Gerritsen's (1975) palette, comprising a range of the spectral colors along with black, white, and gray. Although the latter three are achromatic and not considered colors for the purposes of some formal color systems, phenomenologically they are experienced as distinctive hues and were thus included.

An online survey was conducted in late 2004, and 127 useable responses for the questions on color were received from respondents in Australia and globally. This study is detailed elsewhere (Donald \& Gammack, 2005) and corroborated our findings from other studies (e.g., Gammack, 2004) about the characteristic colors of Sydney and Hong Kong. Figure 1 shows the proportion of respondents identifying each city with a color on Gerritsen's palette. Orange had relatively few responses and was combined with red for analysis.

Sydney emerges as overwhelmingly in the blue range of the spectrum, with both Hong Kong and Shanghai in the red/orange area, and more similar to one another than to Sydney. These differences are highly significant on a chi square analysis $(p<0.001)$. Reasons attributed for this choice, taking the most frequently occurring terms in the responses, are unsurprisingly (for Sydney) the blue sky, the harbor, the water, and the clear light, whereas for Hong Kong (which of course also has a harbor) the association is less literal, with the energy and vibrancy, dynamism and initiative featuring as salient characteristics, with the red sailed junk and neon signage among the only physically red features, and less frequently mentioned. Tourism promotional films for Hong Kong emphasize this buzz, while with Sydney the promotion is rather more hedonistically based around the possibilities of the outdoor life. As a marker of the everyday in film and television, blocs of solid color (blue) and literal depictions of the water are a strong feature of Sydney locations, while nightshoots, fast cutting, and red tones are more characteristic of Hong Kong. 
Colours for Sydney, Shanghal and Hong Kong

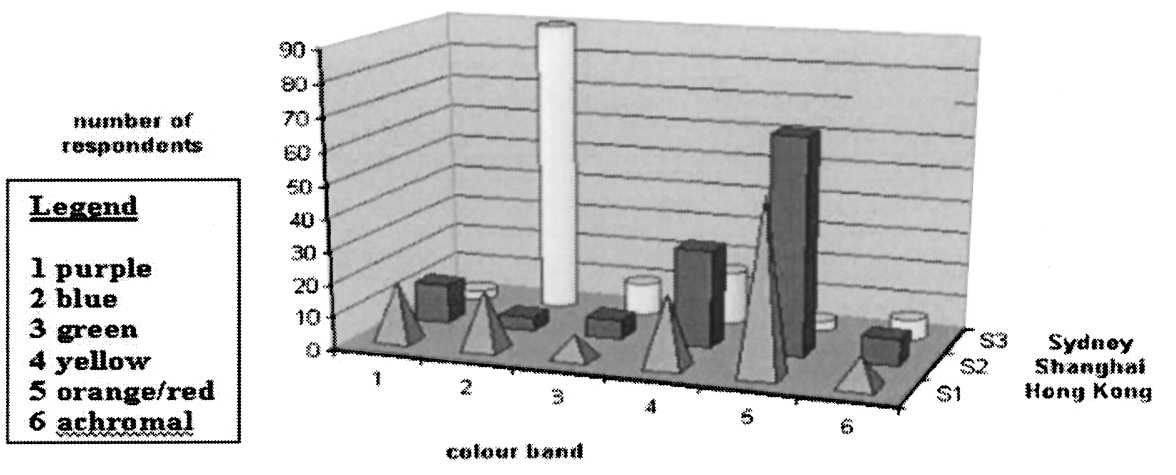

Figure 1. Colors associated with Sydney, Shanghai, and Hong Kong.

\section{Other Studies}

We have also conducted various pilot studies, ministudies, and both informal and formal interviews with relevant logo designers, brand managers, architectural lighting professionals and other creative people. Repertory grids (Kelly, 1955) and map drawing tasks, following Lynch's (1960) method, have also been used to elicit the perspectives of residents and visitors on the salient features of the city (Donald \& Gammack, 2005). Surveys conducted with tourists, residents, and professionals asking about colors and descriptive adjectives (including for other major Australian cities) indicated that cities could be meaningfully distinguished by a characteristic color. Though not detailed here, street interviews of tourists were conducted in the cities, and elsewhere, on abbreviated versions of the questionnaire, focusing particularly on color and key descriptive adjectives. This allowed qualified confirmation of the general validity of the responses from elsewhere, and further context for interpreting findings. For example, yellow, not blue, was not the color perceived most strongly for Brisbane in 99 responses, primarily from tourists (both domestic and international), implying a city-specific rather than national effect. In Hong Kong, a survey of 64 residents affirmed that red was modally perceived as the color of that city, attributed to energy, life, bustle, and action.

This section has outlined a sample of our studies; we are in the process of replicating some of these in each city to allow comparison. Studies are planned using cultural probes (Gaver, Dunne, \& Pacenti, 1999), particularly using postcards, designed to record suggestive story fragments and elements that can be used to design further studies and proposals in multinarrative settings. Discussions and content analysis around sets of logos, tourism brochures, and representative publications are also ongoing.

\section{Conclusions}

In this article we have been concerned with the activity of investigating city branding, and our conclusions firstly reflect on our methods and the project of collaboration, and secondly, on some of our substantive findings on city character that may be further theorized within (or without) disciplinary frameworks.

Our meetings with respondents use(d) textual, visual, and cinematic elicitation (film extracts, stories, postcards); occupation-specific focus groups (cinematographers, urban planners, audience members, backpackers); extended administered questionnaires (senior strategists and directors); location-based surveys (street interviews); and cross-referencing to image-based content and cluster analysis, participant observation, and concept mapping.

Our aim in data collection has been qualitative insight rather than quantitative information, and while our survey samples were large enough to 
suggest the phenomena are consensually real and substantial, our approach has used a range of methods, aiming to abstract what is at work in impressions of place salience. A plexus of research lines converges around the topic of branding cities, and beyond triangulation, a crystal (see Richardson, 2000) may be a better metaphor to guide inquiry. Any one of our methods can be applied systematically within disciplinary agendas (and traditionally have been), but the value in our experience of interdisciplinarity has been in reflecting other lights on only rigorously conceived research.

In branding research, with its rational and emotional aspects, rather than independent lines of discipline-based enquiry, we have sought to establish an interdisciplinary ground for research, upon which we can adopt common methods and constructs, and understand them by reference both to their critical pedigree and their practical outcomes. We found that narrative, structures of attention, and color offered rich possibilities for theory construction and either "scientific" experimentation or "humanistic" critique, as appropriate.

We believe that cross-disciplinary collaboration and techniques allow both parties to pose questions in mutually decipherable ways, and to present them to each other and to a wider audience. This particular collaboration has helped build a vocabulary for describing complex discipline-specific ideas to nonacademics, such as tourism marketers, branding professionals, and film and documentary makers. This has not compromised our research duty to transcribe their equally complicated relationships with the city into meaningful notations for theoretical purposes. Finally, however, we would contend that the real worth of our collaboration is that we begin to understand the structurations of thought that we share as city dwellers, professionals, and professional thinkers.

\section{Acknowledgements}

We acknowledge funding for this project from 2003-2005 through the Australian Research Council Discovery Grant scheme, DP 0342966. We also thank all the participants in our studies, and thank A/Prof Catherine Yuk Kiu Poon, of the
Department of Hotel, Service \& Tourism Studies, Hong Kong Institute of Vocational Education, Chai Wan for her help in administering the survey in Hong Kong.

\section{References}

Beasley, R. (2001). Hell has harbour views. Sydney: Pan Macmillan Australia.

Carroll, J. M. (1999). Chinese collaboration in the making of British Hong Kong. In Tak-wing Ngo (Ed.), Hong Kong's history: State and society under colonial rule (pp. 13-29). London: Routledge.

City of Glasgow. (2004). Glasgow's Miles Better. Retrieved March 15, 2004, from http://www.glasgow.gov.uk/en/ YourCouncil/PublicRelations/Campaigns/glasgowsmiles better.htm

Damasio, A. R. (1994). Descartes' error: Emotion, reason, and the human brain. New York: Avon Books.

Denzin, N. K., \& Lincoln, Y. S. (2000). Handbook of qualitative research (2nd ed.). Thousand Oaks, CA: Sage.

Donald, S. H. (2004). Hong Kong 1:99: SARS, and storytelling in a special autonomous region. In S. H. Donald (Ed.), Creative cities: Cinema and the built environment (pp. 42-49). Brisbane: QUT.

Donald, S. H., \& Gammack, J. (2001a). Nations online: Virtual tourism and political transition. Paper presented at Cultural Studies Association of Australia Conference, "What's Left of Theory?", University of Tasmania, Hobart, December 8-10.

Donald, S. H., \& Gammack, J. (2001b). Virtual tourism and new media citizenships in Scotland and Hong Kong: Complementary case studies. Invited paper presented at International Conference "Media and Culture Development in the Digital Era," Taipei, March 28-30, 2001. Retrieved March 19, 2005, from http://wwwmcc .murdoch.edu.au/ReadingRoom/VID/tourist.html

Donald, S. H., \& Gammack, J. (2004). Branding cities: A case study of collaborative methodologies in cultural, film, and marketing research. In M. Gibson, D. Rodan, F. Newman, R. Blaber, W. Parkins, G. Craig, \& C. Gordon, Everyday transformations: The twenty-first century quotidian, Proceedings of the Cultural Studies Association of Australia Conference, Perth, December. Retrieved March 19, 2005, from http://wwwmcc.murdoch.edu.au/cfel/docs/Donald_GammackFV.pdf

Donald, S. H., \& Gammack, J. (2005). Drawing Sydney: Flatlands, chromatics and the cinematic contours of a world's global city. SCAN: Journal of Media Arts Culture, 2(1). Retrieved May 26, 2005, from www.scan .net.au/scan/journal/0405/refereed.php

Donald, S. H., \& Gammack, J. G. (in preparation). Branding cities: Cinema, tourism, and urban identity on the West Pacific Rim. Manuscript in preparation.

Elkins, J. (2002). Stories of art. London: Routledge.

Eloff, I., Engelbrecht, P., Kozleski, E., Oswald, M., Swart, E., \& Yssel, N. (2002). Epistemological and method- 
ological issues in a transatlantic research project on inclusive education. Paper presented at Australian Association for Research in Education, December 2002, Brisbane. Retrieved March 18, 2005, from http://www .aare.edu.au/02pap/elo02038.htm

Florida, R. (2002). The rise of the creative class: And how it's transforming work, leisure, community and everyday life. New York: Basic Books.

Gammack, J. G. (2004). Colour and the city: Sydney. In S. H. Donald (Ed.), Creative cities: Cinema and the built environment (pp. 50-55). Brisbane: QUT.

Gammack, J. G., Goulding, P., \& Seow, H. H. (2002). Communicating regional identity: The Hong Kong tourism board website. In F. Sudweeks \& C. Ess (Eds.), Cultural attitudes to technology and communication 02 (pp. 237-258). Perth: Murdoch University.

Gaver, B., Dunne, T., \& Pacenti, E. (1999). Cultural probes. Interactions, 6(1), 21-29.

Gentle, N. (2003, October 25). HK 'beset by branding buffoonery.' South China Morning Post.

Gerritsen, F. (1975). Theory and practice of color. London: Studio Vista.

Kelly, G. (1955). The psychology of personal constructs. New York: WW Norton.

Livingston, S. (2004). Projective techniques-10 examples. Retrieved March 19, 2005, from http://www.tlgonline .com/art/020731.shtml

Lynch, K. (1960). The image of the city. Boston: MIT press.

Madriz, E. (2000). Focus groups in feminist research. In
N. K. Denzin \& Y. S. Lincoln (Eds.), Handbook of qualitative research (2nd ed.). Thousand Oaks, CA: Sage.

Morgan, N., Pritchard, A., \& Pride, R. (2004). Destination branding (2nd ed.). London: Butterworth-Heinemann.

Olins, W. (2004). On $b^{\circledast}$ and. London: Thames and Hudson.

Pike, S. (2004). Destination positioning slogans—analysis of themes used by New Zealand regional tourism organizations. In J. Wiley \& P. Thirkell (Eds.), Marketing accountabilities and responsibilities, Proceedings of ANZMAC 2004. Retrieved March 29, 2005, from http:// 130.195.95.71:8081/WWW/ANZMAC2004/CDsite/ papers/Pike1.PDF

Richardson, L. (2000). Writing: A method of inquiry. In N. K. Denzin \& Y. S. Lincoln (Eds.), Handbook of qualitative research (2nd ed.). Thousand Oaks, CA: Sage.

Stohr, K. (2003, March 17). I sell New York. Gotham Gazette. Retrieved March 15, 2005, from http://www .gothamgazette.com/article/issueoftheweek/20030315/ 200/312

Temporal, P. (2000). Branding in Asia: The creation, development and management of Asian brands for the global market. Singapore: John Wiley and Sons.

Uriely, N. (2005). The tourist experience: Conceptual developments. Annals of Tourism Research, 32(1), 199216.

Ward, S. V. (1998). Selling places: The marketing and promotion of towns and cities, 1850-2000. London: Routledge. 